\title{
Alterations in oral microbial flora induced by waterpipe tobacco smoking
}

This article was published in the following Dove Press journal: International Journal of General Medicine

\section{Muhamad Ali K Shakhatreh' Omar F Khabour' \\ Karem H Alzoubi ${ }^{2}$ \\ Majed M Masadeh ${ }^{3}$ \\ Emad I Hussein ${ }^{4}$ \\ George N Bshara'}

'Department of Medical Laboratory Sciences, Faculty of Applied Medical Sciences, Irbid, Jordan; ${ }^{2}$ Department of Clinical Pharmacy, Faculty of Pharmacy, Jordan University of Science and Technology, Irbid, Jordan; ${ }^{3}$ Department of Pharmaceutical Technology, Faculty of Pharmacy, Jordan University of Science and Technology, Irbid, Jordan; ${ }^{4}$ Department of Biological Sciences, Yarmouk University, Irbid, Jordan
Correspondence: Muhamad Ali K Shakhatreh

Department of Medical Laboratory Sciences, Faculty of Applied Medical Sciences, Jordan University of Science and Technology, PO Box 3030, Irbid 221 10, Jordan

Tel +96227201000 ext 23874

Email mkshakhatreh@just.edu.jo
Background: Waterpipe smoking is a global health problem and a serious public concern. Little is known about the effects of waterpipe smoking on oral health. In the current study, we examined the alterations of oral microbial flora by waterpipe smoking.

Methods: One hundred adult healthy subjects (59 waterpipe smokers and 41 non-smokers) were recruited into the study. Swabs were taken from the oral cavity and subgingival regions. Standard culturing techniques were used to identify types, frequency, and mean number of microorganisms in cultures obtained from the subjects.

Results: It was notable that waterpipe smokers were significantly associated with a history of oral infections. In subgingiva, Acinetobacter and Moraxella species were present only in waterpipe smokers. In addition, the frequency of Candida albicans was higher in the subgingiva of waterpipe smokers ( $p=0.023$ ) while the frequency of Fusobacterium nucleatum was significantly lower in the subgingiva of waterpipe smokers $(p=0.036)$. However, no change was observed in other tested bacteria, such as Campylobacter species; Viridans group streptococci, Enterobacteriaceae, and Staphylococcus aureus. In oral cavity and when colony-forming units were considered, the only bacterial species that showed significant difference were the blackpigmented bacteria $(p<0.001)$.

Conclusion: This study provides evidence indicating that some of the oral microflora is significantly altered by waterpipe smoking.

Keywords: waterpipe, smoking, oral microflora, hookah, tobacco

\section{Introduction}

Waterpipe is a way of tobacco consumption in which the smoke passes through the water before it is inhaled. ${ }^{1}$ The use of waterpipes is increasing all over the world, especially among young people and women. ${ }^{2}$ A waterpipe machine has four major parts: a head, stem, vase, and hose (Figure 1). Smoking using this machine includes the use of flavored and hydrated, tobacco known as "moassel." A charcoal is placed on top of the tobacco to provide the heat needed to burn the moassel. ${ }^{1}$ The bottom of the head has holes in it that passes the produced smoke to the stem, which is submerged in water that half-fills the vase. The hose is not submerged, exits from the bowl's top, and ends with a mouthpiece, from which the user inhales. ${ }^{1}$

The health effects of cigarette smoking are well documented; however, knowledge regarding the impact of waterpipe smoking on body health is still lacking. ${ }^{3}$ Previous literature has shown that smoke produced by a waterpipe contains a similar toxicant profile to that produced by cigarettes with different magnitude. For example, the tar 


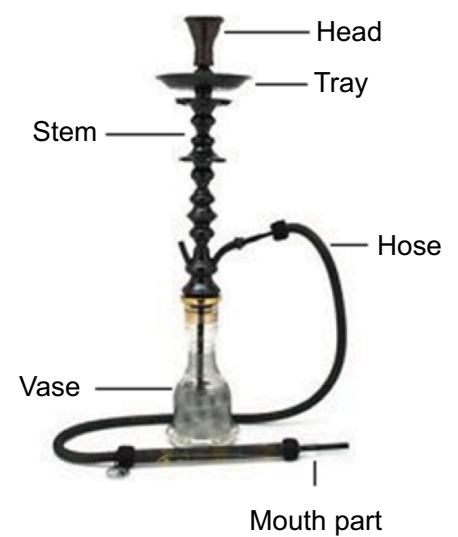

Figure I A waterpipe machine. The major components of a waterpipe machine are labeled and include the head, stem, vase, and hose.

produced by a single episode of waterpipe is about five times that produced by a single cigarette. ${ }^{4}$ Similarly, exposure to carbon monoxide is at least several folds higher during waterpipe smoking compared with that of cigarette smoking. ${ }^{5}$ Furthermore, the polycyclic aromatic hydrocarbons in waterpipe smoke are many times more than that of cigarette smoke. ${ }^{6}$ In addition, the style of waterpipe smoking results in a dramatically higher exposure volume to smoke, more tobacco consumption per smoking event, and longer smoke inhalation periods. ${ }^{7}$ Finally, tobacco in waterpipes is usually mixed with sugar, glycerol, and flavors, this mixture is burned by charcoal. ${ }^{1}$ Thus, it is expected that waterpipe smoking will have a distinct effect on oral microbial flora.

The effects of cigarette smoking on oral health show that cigarette smoking is associated with oral cancer, periodontal disease, oral infections, and interference with the taste and modulation of normal flora ${ }^{8,9}$ Several studies have also investigated the effect of smoking on oral microbiota and showed significant differences in the subgingival bacteria between smokers and non-smokers, ${ }^{10}$ For example, Zambon reported that smokers harbored significantly higher levels of Bacteroides forsythus subgingivally. ${ }^{11}$ In addition, the prevalence of several oral pathogens such as Prevotella nigrescens, Prevotella intermedia, Porphyromonas gingivalis, and Tannerella was significantly higher in smokers than in non-smokers. ${ }^{12}$ Regarding waterpipe smoking, few studies have examined effects of waterpipe smoking on oral health. A recent study has shown a strong association between waterpipe smoking and periodontal disease. ${ }^{13}$ In addition, waterpipe smoking has been shown to significantly increase potentially malignant oral mucosal lesions ${ }^{14}$ and lower lip squamous cell carcinoma and keratoacanthoma. ${ }^{15}$ Moreover, waterpipe smoking has been shown to induce DNA damage in buccal cells. ${ }^{16}$
Several bacterial species were identified in the human oral cavity including many anaerobic periodontal pathogens which are associated with periodontal infections such as P. gingivalis, Tannerella forsythia, P. intermedia, Eikenella corrodens, Campylobacter rectus, Aggregatibacter actinomycetemcomitans, Treponema denticola, and Fusobacterium nucleatum. ${ }^{17}$ The frequency of these pathogens in the oral cavity has been shown to be altered by cigarette smoking. ${ }^{18}$ Since the profile of toxicants and behavior of smoking are different between waterpipe and cigarette smoking, in this study, we investigated the effect of waterpipe smoking on the profile of normal flora in the oral cavity and subgingiva which is still undefined and unclear. The results of this study might be used to derive policies and interventions that target waterpipe smokers.

\section{Materials and methods Subjects}

Fifty-nine healthy waterpipe smokers were recruited to participate in the study. As a control, 41 healthy non-smokers that matched the smokers group in gender and age were also recruited from the same geographical area. Smokers and their matched controls were recruited from customers of waterpipe cafes in Irbid city, which is the largest urban population north of Jordan. Usual customers of waterpipe cafes are young adults of both genders, who are either waterpipe smokers or waterpipe non-smokers who accompany their smoking friends, relatives, or family members to these places. Those who used tobacco products other than waterpipe were excluded from the study. Additionally, participants with previous history of oral diseases/infections or who were taking medications during the past 2 months were also excluded from the study. This study was approved by the Institutional Review Board of Jordan University of Science and Technology (Approval number 152/2012), and written informed consent was obtained from all subjects according to Institutional Review Board approval.

\section{Sample collection}

Subgingival samples were collected by inserting and rotating absorbent sterile paper-points (Meta Biomed Co Ltd, Cheongju, South Korea) for 10-15 seconds between the front upper and lower teeth to get high quantities of bacteria. Subjects with bleeding gums were excluded. In addition, any participant with a history of oral infection in the past 2 months was excluded. Oral cavity samples (teeth, tongue, and cheeks) were collected using sterile cotton transport swabs. Occasionally, bleeding occurred while taking the 
sample after inserting and rotating the sterile paper points (one for lower part and one for the upper part of teeth). In this case, the sample was discarded and sampling was repeated from a non-bleeding site. Samples were transported under anaerobic conditions using liquid dental transport medium (LDTM) (Anaerobe Systems, Morgan Hill, CA, USA). All samples were processed for microbiology techniques within 1-2 hours.

\section{Culture conditions}

Isolation of microorganisms was carried out by methods previously reported. ${ }^{19}$ Isolated strains were characterized using standard microbiological methods as described in Clinical and Laboratory Standards Institute (CLSI) ML35$\mathrm{A} 2^{20}$ document (Table 1). Each sample was vortexed at high speed for 60 seconds and then subjected to a series of 10 -fold dilutions (up to $10^{-4}$ ) by using sterile Dulbecco's phosphate buffered saline. Thereafter, aliquots of $100 \mu \mathrm{L}$ from each different dilution were spread onto different differential and selective media including: crystal violet erythromycin (CVE), Wolinella agar, MacConkey agar, mannitol salt agar (MSA), kanamycin-vancomycin laked blood-2 (KVLB-2), tryptic soy agar supplemented with hemin $5 \mathrm{mg} / \mathrm{mL}$ and vitamin $\mathrm{K} 3$ (Menadione) $0.5 \mu \mathrm{g} / \mathrm{mL}$, Mitis Salivarius agar supplemented with tellurite solution, and Sabouraud dextrose agar (SDA). For each microbial species, colony-forming units (CFUs $/ \mathrm{mL})$ were recorded for each plate by CFU enumeration assay. Total counts were determined on Columbia blood agar, aerobically and anaerobically. The following media were inoculated and incubated anaerobically at $37^{\circ} \mathrm{C}$ for $7-10$ days by using the Oxoid ${ }^{\mathrm{TM}}$ Anaerobic Atmosphere Generation System, AnaeroGen $^{\text {TM }}$ 2.5 L Sachets: 1; ThermoFisher Scientic, Waltham, MA, USA) CVE agar (trypticase soy agar, yeast extract $5 \mathrm{~g} / \mathrm{L}$, sodium chloride $5 \mathrm{~g} / \mathrm{L}$, glucose $2 \mathrm{~g} / \mathrm{L}$, tryptophan $0.2 \mathrm{~g} / \mathrm{L}$, crystal violet $5 \mathrm{mg} / \mathrm{L}$, erythromycin $4 \mathrm{mg} / \mathrm{L}$, defibrinated sheep blood $50 \mathrm{~mL} / \mathrm{L}$ ) was used to assess $F$. nucleatum; ${ }^{21}$ 2) Kanamycin Vancomycin Laked Blood-2 (KVLB-2: Kanamycin $75 \mu \mathrm{g} / \mathrm{mL}$, Vancomycin $2 \mu \mathrm{g} / \mathrm{mL}$, laked blood) supplemented with hemin $5 \mu \mathrm{g} / \mathrm{mL}$, vitamin $\mathrm{K} 11 \mu \mathrm{g} / \mathrm{mL}$ ), and trypticase soy agar supplemented with (hemin $5 \mathrm{mg} / \mathrm{mL}$, Vitamin K3 $0.5 \mu \mathrm{g} / \mathrm{mL}$, sheep blood) were used to assess the black-pigmented P. intermedia and P. gingivalis, respectively; and 3) Wolinella agar (trypticase soy agar, vancomycin $9 \mu \mathrm{g} /$ $\mathrm{mL}$, ferrous sulfate $0.2 \mathrm{~g} / \mathrm{L}$, sodium thiosulphate $0.3 \mathrm{~g} / \mathrm{L}$, sodium fumarate $3 \mathrm{~g} / \mathrm{L}$, sodium formate $2 \mathrm{~g} / \mathrm{L}$ ) was used for the isolation of $C$. rectus. ${ }^{22}$

MSA was used to identify aerobic species such as Staphylococcus aureus and S.epidermidis. Yeast cells Candida albicans were identified by SDA. Species of Enterobacteriaceae family were identified on MacConkey agar and depending on the following tests: Gram stain, citrate test, motility test, urease test, indole test, oxidase test, catalase test, and triple sugar iron (TSI) agar. Mitis Salivarius Agar with 1\% potassium tellurite was used to detect oral viridans streptococci, which consists of Streptococcus mutans, S. salivarius, and S. mitis.

For the determination of total aerobic and anaerobic bacteria counts for each microbial species, $\mathrm{CFUs} / \mathrm{mL}$ were recorded for each plate by using the $\mathrm{CFU}$ enumeration assay. Bacteria were grown on Columbia blood agar under: 1) aerobic condition: $35^{\circ} \mathrm{C} \pm 2^{\circ} \mathrm{C}$ for $18-72$ hours under appropriate atmospheric conditions; and 2) anaerobic condition: $37^{\circ} \mathrm{C}$ for 7-10 days by using AnaeroGen $2.5 \mathrm{~L}$ sachets.

\section{Statistical analysis}

Statistical analyses were conducted using SPSS software (version 17). Comparison of frequency of bacteria and pathogens between waterpipe smokers and control groups was

Table I Culture media used in the current study

\begin{tabular}{|c|c|c|}
\hline Culture media & Identified microorganisms & Additional identification procedures \\
\hline CBA & Aerobic and anaerobic & None \\
\hline CVE & Fusobacterium nucleatum & Distinct colonial morphology of $F$. nucleatum on CVE agar \\
\hline KVLB-2 & The black-pigmented Prevotella intermedia & $\begin{array}{l}\text { Characteristic colonial growth and morphology, special-potency antibiotic } \\
\text { disks, }\end{array}$ \\
\hline MacConkey agar & Enterobacteriaceae & $\begin{array}{l}\text { Gram stain, citrate test, motility test, urease test, indole test, oxidase test, } \\
\text { catalase test, and TSI agar }\end{array}$ \\
\hline MSA & $\begin{array}{l}\text { Staphylococcus aureus and Staphylococcus } \\
\text { epidermidis }\end{array}$ & Colony morphology and colors \\
\hline Mitis Salivarius agar & Oral viridans streptococci & Colony morphology and colors \\
\hline SDA & Candida albicans & Colony morphology and colors \\
\hline Tryptic soy agar & Porphyromonas gingivalis & Colony morphology, biochemical tests, fluorescence test \\
\hline
\end{tabular}

Abbreviations: CBA, Columbia blood agar; CVE, crystal violet erythromycin; KVLB, kanamycin-vancomycin laked blood; MSA, mannitol salt agar; SDA, Sabouraud dextrose agar; TSI, triple sugar iron. 
conducted using the Mann-Whitney $U$-test (as data were not normally distributed), and chi-square test. CFU values were expressed as mean \pm standard error of the mean (SEM) and were compared between different groups using the MannWhitney $U$-test (as data was also not normally distributed). Significant differences were examined at $p<0.05$. Power analysis was carried out using $G$ power version 3.0.10 (Franz Faul, Universtat Kiel, Germany). Sample size analysis was performed at $80 \%$ and $5 \% \alpha$-level of significance.

\section{Results}

The characteristics of study participants are shown in Table 2. The mean age of the waterpipe group was $23.98 \pm 2.77$ years versus $24.14 \pm 4.37$ years in the control group $(p=0.8)$. Males represented $74.5 \%$ of the waterpipe group and $65.9 \%$ of the control group. The average smoke sessions in waterpipe group per week were $4.98 \pm 2.12$. It was notable that waterpipe smokers were significantly associated with a history of oral infections $(p=0.01)$. Table 3 shows the distribution of bacterial species isolated from subgingiva of participants. The most abundant bacteria from examined species were viridans streptococci, $C$. rectus and $F$. nucleatum in waterpipe users (range 84\%-94\%) and in non-smokers (range: 85\%-97\%). Acinetobacter and Moraxella species were present only in waterpipe smokers with a frequency of $5.1 \%$ and a mean of 31.7. The frequency of $F$. nucleatum was significantly lower in subgingiva of waterpipe smokers ( $p=0.036$, Figure 2A) while the frequency of $C$. albicans was higher in waterpipe smokers $(p=0.023$, Figure $2 B)$. Finally, the profile of the remaining examined bacteria was similar between the two groups $(p>0.05)$.

Table 4 shows the distribution of bacterial species isolated from the oral cavity of participants. The most abundant

Table 2 Characteristics of participants

\begin{tabular}{|c|c|c|c|}
\hline Characteristics & Waterpipe group & Control group & $p$-value \\
\hline Age, years (mean \pm SD) & $23.98 \pm 2.77$ & $24.14 \pm 4.37$ & 0.8 (using Mann-Whitney U-test) \\
\hline Age range, years & $19-32$ & $19-35$ & \\
\hline \multicolumn{4}{|l|}{ Gender } \\
\hline Male & $44(74.5 \%)$ & 27 (65.9\%) & 0.4 (using $\chi^{2}$ test) \\
\hline Female & $15(25.5 \%)$ & $14(34.1 \%)$ & \\
\hline \multicolumn{4}{|l|}{ History of oral infection } \\
\hline Yes & $38(64.4 \%)$ & $16(39.0 \%)$ & 0.01 (using $\chi^{2}$ test) \\
\hline No & $21(35.6 \%)$ & $25(61.0 \%)$ & \\
\hline Waterpipe use: sessions per week (mean \pm SD) & $4.98 \pm 2.12$ & - & \\
\hline \multicolumn{4}{|l|}{ Duration of WP session, minutes } \\
\hline Less than 30 & $12(20.3 \%)$ & - & \\
\hline $30-60$ & $29(49.2 \%)$ & & \\
\hline $61-90$ & $15(25.4 \%)$ & & \\
\hline More than 90 & $3(5.1 \%)$ & & \\
\hline \multicolumn{4}{|l|}{ Age of initiation, years } \\
\hline Less than 14 & $3(5.1 \%)$ & - & \\
\hline $15-17$ & 14 (23.7\%) & & \\
\hline$|8-2|$ & 30 (50.9\%) & & \\
\hline More than 21 & $12(20.3 \%)$ & & \\
\hline
\end{tabular}

Abbreviations: SD, standard deviation; WP, waterpipe.

Table 3 Frequency and CFUs of isolates of detected microorganisms from subgingival plaque of participants

\begin{tabular}{lllllll}
\hline Microorganisms (oral) & $\begin{array}{l}\text { Waterpipe } \\
\text { frequency, } \\
\mathbf{N}(\%)\end{array}$ & $\begin{array}{l}\text { Controls } \\
\text { frequency, } \\
\mathbf{N}(\%)\end{array}$ & $\begin{array}{l}\boldsymbol{p} \text {-value, } \\
\boldsymbol{X}^{2} \text { test }\end{array}$ & $\begin{array}{l}\text { Waterpipe } \\
\text { CFU, } \\
\text { mean } \pm \text { SD }\end{array}$ & $\begin{array}{l}\text { Controls } \\
\text { CFU, } \\
\text { mean } \pm \text { SD }\end{array}$ & $\begin{array}{l}\text { Mann- } \\
\text { Whitney } \\
\text { U-test } \boldsymbol{p} \text {-value }\end{array}$ \\
\hline Fusobacterium nucleatum & $50(84.7)$ & $36(97.6)$ & 0.036 & $3.9 \pm 8.9$ & $3.1 \pm 7.6$ & 0.49 \\
Black-pigmented bacteria & $43(68.3)$ & $29(78.4)$ & 0.31 & $3.3 \pm 3.6$ & $11.0 \pm 31.9$ & 0.69 \\
Campylobacter spp. & $52(88.1)$ & $38(92.7)$ & 0.52 & $5.16 \pm 26.8$ & $83.6 \pm 209.2$ & 0.33 \\
Viridans group streptococci & $55(93.2)$ & $35(85.4)$ & 0.20 & $99.7 \pm 320.9$ & $130.1 \pm 408$ & 0.58 \\
Acinetobacter and Moraxella & $3(5.1)$ & $0(0)$ & 0.14 & $31.7 \pm 38.8$ & 0 & - \\
Enterobacteriaceae & $7(I I .9)$ & $3(7.35)$ & 0.456 & $0.02 \pm 0.03$ & $0.03 \pm 0.02$ & 0.25 \\
Staphylococcus aureus & $2(3.4)$ & $4(9.8)$ & 0.19 & $0.01 \pm 0.02$ & $0.01 \pm 0.01$ & 0.10 \\
Yeast (Candida albicans) & $10(16.9)$ & I (2.45) & 0.023 & $0.1 \pm 0.4$ & $0.01 \pm 0.0$ & 0.63 \\
\hline
\end{tabular}

Abbreviations: CFU, colony-forming units; SD, standard deviation. 
bacteria from examined species were viridans streptococci, Campylobacter spp. F. nucleatum and black-pigmented bacteria in waterpipe users (range $94 \%-100 \%$ ) and in non-smokers (range: $92 \%-96 \%$ ). From these abundant bacteria, the mean of CFUs of black-pigmented bacteria was significantly lower ( $p$ $=0.001$, Figure 3 ) in waterpipe smokers. Finally, no significant variations were detected in the distribution or mean of the rest of examined bacteria between the two groups $(p>0.05)$.

\section{Discussion}

The popularity of waterpipe smoking is growing in the Eastern Mediterranean and throughout the world, including
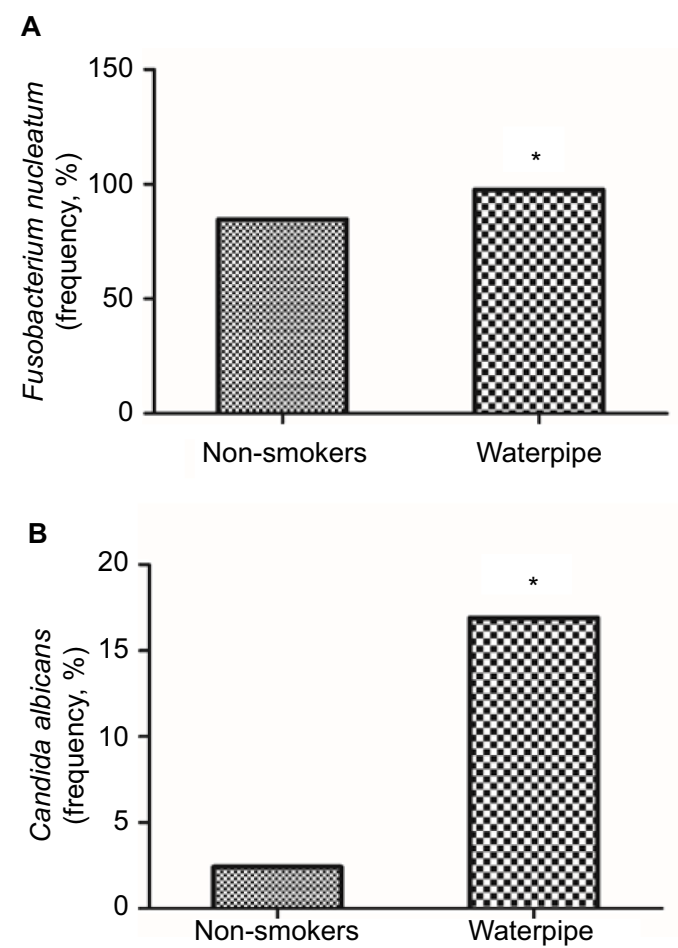

Figure 2 Frequency of some microbes in the waterpipe smokers isolated from the subgingiva of participants. Significant changes in the frequency of (A) Fusobacerium nucleatum and (B) Candida albicans in the subgingiva of participants. *Indicates significant changes $(p<0.05)$ using the chi-square test. the USA and other Western countries, especially among youth..$^{23}$ This spread is due, in part, to the use of tobacco that is sweetened and flavored ${ }^{24}$ and the misperception that the waterpipe "filters" the smoke, rendering it less harmful and less dependent than cigarette smoke. ${ }^{25}$ While prevalence increases, science lags behind: little is known about harmful effects of the waterpipe on different body organs and whether or not it causes dependence.

The current study was performed to investigate the effect of waterpipe tobacco smoking (WTS) on oral and subgingival microbial flora. Variations were shown in the microbial profile of waterpipe smokers as compared to that of non-smokers, with significant differences in the prevalence and abundance of health-compatible organisms.

The limited information concerning the waterpipe effects on health could represent a major reason for its massive spread globally. ${ }^{26}$ It has been reported that waterpipe smokers inhale similar toxicants to that of cigarettes smoking ${ }^{4}$ including polycyclic aromatic hydrocarbons, ${ }^{6}$ carbon monoxide, heavy metals, and aldehydes. ${ }^{5}$ In addition, WTS has been shown to increase DNA damage in the lymphocytes and buccal mucosa cells of the users. ${ }^{27}$ Lately, waterpipe tobacco smoking was reported to interfere with respiratory

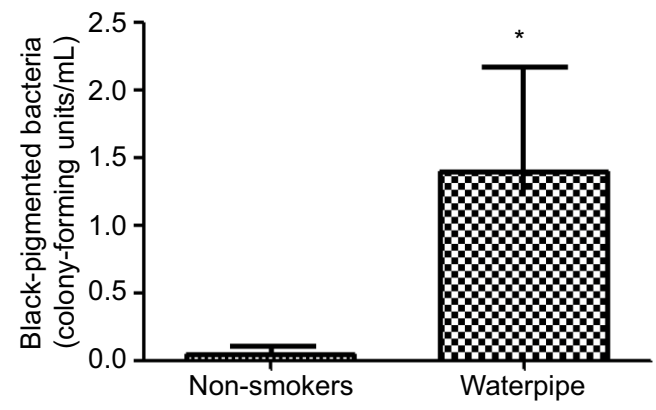

Figure 3 Frequency of some microbes in the waterpipe smokers isolated from the oral cavity of the participants. Significant changes in the frequency of blackpigmented bacteria. *Indicates significant changes $(p<0.05)$ using the chi-square test.

Table 4. Frequency and CFUs of isolates of detected microorganisms from oral cavity of participants

\begin{tabular}{|c|c|c|c|c|c|c|}
\hline Microorganisms (oral) & $\begin{array}{l}\text { Waterpipe } \\
\text { frequency, } \\
\text { N (\%) }\end{array}$ & $\begin{array}{l}\text { Controls } \\
\text { frequency, } \\
\text { N (\%) }\end{array}$ & $\begin{array}{l}p \text {-value, } \\
X^{2} \text { test }\end{array}$ & $\begin{array}{l}\text { Waterpipe } \\
\text { CFU, } \\
\text { mean } \pm \text { SD }\end{array}$ & $\begin{array}{l}\text { Controls } \\
\text { CFU, } \\
\text { mean } \pm \text { SD }\end{array}$ & $\begin{array}{l}\text { Mann- } \\
\text { Whitney } \\
\text { U-test p-value }\end{array}$ \\
\hline Fusobacterium nucleatum & $55(93.2)$ & $40(97.6)$ & 0.327 & $0.42 \pm 0.43$ & $6.44 \pm 36.4$ & 0.20 \\
\hline Black-pigmented bacteria & $40(63.5)$ & $18(48.7)$ & 0.15 & $1.4 \pm 0.7$ & $0.05 \pm 0.04$ & 0.001 \\
\hline Campylobacter spp. & $57(96.1)$ & $38(92.7)$ & 0.38 & $0.60 \pm 0.74$ & $0.72 \pm 0.74$ & 0.38 \\
\hline Viridans group streptococci & $59(100)$ & $39(95.1)$ & 0.087 & $37.6 \pm 30.4$ & $36.9 \pm 39.0$ & 0.69 \\
\hline Acinetobacter and Moraxella & $4(6.8)$ & $4(9.8)$ & 0.59 & $0.26 \pm 0.30$ & $0.13 \pm 0.25$ & 0.49 \\
\hline Enterobacteriaceae & I5 (25.4) & $4(9.8)$ & 0.50 & $0.01 \pm 0.01$ & $0.05 \pm 0.08$ & 0.06 \\
\hline Staphylococcus aureus & $5(8.5)$ & $4(9.8)$ & 0.83 & $0.01 \pm 0.01$ & $0.01 \pm 0.01$ & 0.29 \\
\hline Yeast (Candida albicans) & $6(10.2)$ & $6(14.6)$ & 0.50 & $0.01 \pm 0.01$ & $0.01 \pm 0.02$ & 0.31 \\
\hline
\end{tabular}

Note: Significant $p$-value $<0.05$ is shown in bold.

Abbreviations: CFU, colony-forming units; SD, standard deviation. 
and vascular functions, ${ }^{28}$ and to enhance oral diseases. ${ }^{13}$ The results reported in the current study showing changes in oral microflora are in accordance with the above findings. This is particularly true because most of the bacteria that appeared or were enhanced among waterpipe smokers, can be pathogenic to human. ${ }^{29,30}$

Current results indicated the appearance of Acinetobacter and Moraxella species in subgingiva of waterpipe smokers. Both of these bacterial species are a common cause of human respiratory diseases. For example, a common $\mathrm{Aci}$ netobacter species is Acinetobacter baumannii, which can cause community-acquired pneumonia. ${ }^{29,31}$ Another common Moraxella species is Moraxella catarrhalis, which causes upper and lower respiratory infections, sinusitis and otitis media in susceptible humans. ${ }^{32,33}$ Notably, for both former mentioned species, tobacco consumption is a listed risk factor for infections. ${ }^{29}$

The results of this study showed increased frequency of $C$. albicans in the subgingiva of waterpipe smokers. C. albicans is a part of the normal oral microflora; ${ }^{34}$ however, any increase in its number will lead to oral Candida infection, which is known as oral thrush. ${ }^{30}$ In fact, it has been reported that cigarette smoking increases the incidence of Candida infections in healthy humans. ${ }^{35}$ Additionally, it was shown that exposure to tobacco smoke enhances the virulence of C. albicans. ${ }^{36}$

In this study, black-pigmented bacteria such as $P$. gingivalis and $P$. intermedia had higher CFUs in isolates from the oral cavity of waterpipe smokers. These species are common in the oral cavity and are associated with periodontitis. ${ }^{37}$ Another bacterial species that was reduced in the gingival flora of waterpipe smokers was $F$. nucleateum, which is associated with limited pathogenesis. ${ }^{38}$ In fact, F. nucleatum is one of the most abundant anaerobic species in the oral cavity, in both diseased and healthy individuals. It may normally present in the healthy human oral cavity or considered as periodontal pathogenic. F. nucleatum proportions may be higher in current cigarette smokers. ${ }^{39}$ However, in a study from Jordan, F. nucleatum was less prevalent among cigarettes smokers. ${ }^{40}$ Notably, toxicant profile of waterpipe smoke has been shown to be different from that of cigarette smoke in terms of quantity and types. This could explain such variations observed in the current study as compared to cigarette literature.

Cigarettes smoking was also found to cause alteration in subgingival and oral bacterial profiles. ${ }^{41}$ For example, periodontitis in smokers is associated with greater depletion of beneficial bacteria such as Veillonella, Neisseria, and Streptococcus species. On the other hand, the abundance of harmful bacteria such as Parvimonas, Campylobacter, Treponema, Fusobacterium, and Bacteroides was greatly enhanced in smokers. ${ }^{41,42}$ Only a few studies assessed the effect of WTS on periodontal disease using different outcome measurement such as periodontal bone height loss, plaque index, and gingivitis showing a statistically significant association of periodontal disease with WTS. ${ }^{43}$ This is in support of the findings of the current study.

It is worth mentioning that the waterpipe group showed significantly higher history of oral infection than the control group. This is expected as a previous study showed the presence of a spectrum of pathogenic bacteria in the hoses of waterpipe smokers. ${ }^{44}$ In addition, waterpipe smoking has been shown to be associated with periodontal disease, ${ }^{45}$ and oral cancer. ${ }^{46}$ Moreover, cigarette smoking has also been shown to be associated with oral infection. ${ }^{47}$ Since the sample of the current study was random, the higher history of oral infection in the waterpipe group supported the imbalance in microbial flora induced by this type of smoking.

Public health policy specific to WTS is lacking in many countries. ${ }^{48,49}$ For example, in Jordan legislation requires health warnings on all tobacco products, but these warnings appear on cigarette packs only and not on WTS tobacco or waterpipes. The same is true in the US, where WTS is not yet regulated nationally. The current study highlights the importance of adopting strong policy regarding waterpipes. The knowledge presented in this study might also be used in interventions that target this type of smoking.

One of the limitations of the study was that a good fraction of oral microflora is uncultivable, and cultural techniques cannot differentiate between close bacteria such as Campylobacter spp., the use of other cultivation-independent approaches such as DNA hybridization, q-PCR, and 16S rRNA gene sequencing would be valuable in future investigations. Finally, it is recommended in future investigations to associate altered pathogens by waterpipe smoking with oral diseases by examining their resistance to commonly used antibiotics.

\section{Conclusion}

The study provided preliminary evidence for the effect of waterpipe smoking on oral microbiota.

\section{Acknowledgments}

The abstract of this paper was presented at the 2nd World Congress on Pediatric Care and Pediatric Infectious Diseases and the International conference on Pediatric Care and Pediatric Infectious Diseases as an abstract presentation 
with interim findings. The poster's abstract was published in "Poster Abstracts" in J Infect Dis Ther 2016, 4:4(Suppl).

This work was supported by a grant from the Deanship of Research at Jordan University of Science and Technology (grant number 152/2012 to MAKS and OFK).

\section{Disclosure}

The authors report no conflicts of interest in this work.

\section{References}

1. Shihadeh A. Investigation of mainstream smoke aerosol of the argileh water pipe. Food Chem Toxicol. 2003;41(1):143-152.

2. Jawad M, Abass J, Hariri A, et al. Waterpipe smoking: prevalence and attitudes among medical students in London. Int J Tuberc Lung Dis. 2013;17(1):137-140.

3. Maziak W, Taleb ZB, Bahelah R, et al. The global epidemiology of waterpipe smoking. Tob Control. 2015;24 (Suppl 1):i3-i12.

4. Sepetdjian E, Shihadeh A, Saliba NA. Measurement of 16 polycyclic aromatic hydrocarbons in narghile waterpipe tobacco smoke. Food Chem Toxicol. 2008;46(5):1582-1590.

5. Shihadeh A, Saleh R. Polycyclic aromatic hydrocarbons, carbon monoxide, "tar", and nicotine in the mainstream smoke aerosol of the narghile water pipe. Food Chem Toxicol. 2005;43(5):655-661.

6. Shihadeh A, Azar S, Antonios C, Haddad A. Towards a topographical model of narghile water-pipe cafe smoking: a pilot study in a high socioeconomic status neighborhood of Beirut, Lebanon. Pharmacol Biochem Behav. 2004;79(1):75-82.

7. Cobb C, Ward KD, Maziak W, Shihadeh AL, Eissenberg T. Waterpipe tobacco smoking: an emerging health crisis in the United States. $\mathrm{Am} J$ Health Behav. 2010;34(3):275-285.

8. Haukioja A, Asunta M, Söderling E, Syrjanen S. Persistent oral human papillomavirus infection is associated with smoking and elevated salivary immunoglobulin G concentration. J Clin Virol. 2014;61(1):101-106.

9. Sherwin GB, Nguyen D, Friedman Y, Wolff MS. The relationship between smoking and periodontal disease. Review of literature and case report. N Y State Dent J. 2013;79(6):52-57.

10. Eggert FM, McLeod MH, Flowerdew G. Effects of smoking and treatment status on periodontal bacteria: evidence that smoking influences control of periodontal bacteria at the mucosal surface of the gingival crevice. J Periodontol. 2001;72(9):1210-1220.

11. Zambon JJ. Periodontal diseases: microbial factors. Ann Periodontol. 1996;1(1):879-925.

12. Kononen E, Paju S, Pussinen PJ, et al. Population-based study of salivary carriage of periodontal pathogens in adults. J Clin Microbiol. 2007;45(8):2446-2451.

13. Bibars AR, Obeidat SR, Khader Y, Mahasneh AM, Khabour OF. The effect of waterpipe smoking on periodontal health. Oral Health Prev Dent. 2015;13(3):253-259.

14. Warnakulasuriya S. Waterpipe smoking, oral cancer and other oral health effects. Evid Based Dent. 2011;12(2):44-45.

15. El-Hakim IE, Uthman MA. Squamous cell carcinoma and keratoacanthoma of the lower lip associated with "Goza" and "Shisha" smoking. Int J Dermatol. 1999;38(2):108-110.

16. Al-Amrah HJ, Aboznada OA, Alam MZ, ElAssouli MZ, Mujallid MI, ElAssouli SM. Genotoxicity of waterpipe smoke in buccal cells and peripheral blood leukocytes as determined by comet assay. Inhal Toxicol. 2014;26(14):891-896.

17. D'Ercole S, Catamo G, Piccolomini R. Diagnosis in periodontology: a further aid through microbiological tests. Crit Rev Microbiol. 2008;34(1):33-41.

18. Riep B, Edesi-Neuss L, Claessen F, et al. Are putative periodontal pathogens reliable diagnostic markers? J Clin Microbiol. 2009;47(6):1705-1711.
19. D'Ercole S, Catamo G, Tripodi D, Piccolomini R. Comparison of culture methods and multiplex PCR for the detection of periodontopathogenic bacteria in biofilm associated with severe forms of periodontitis. New Microbiol. 2008;31(3):383-391.

20. Clinical and Laboratory Standards Institute (CLSI). Abbreviated Identification of Bacteria and Yeast, Approved guidlines, 2nd ed. CLSI document ML35-A2. Wayne, PA: CLSI; 2008.

21. Walker CB, Ratliff D, Muller D, Mandell R, Socransky SS. Medium for selective isolation of Fusobacterium nucleatum from human periodontal pockets. J Clin Microbiol. 1979;10(6):844-849.

22. Kamma JJ, Nakou M, Baehni PC. Clinical and microbiological characteristics of smokers with early onset periodontitis. J Periodontal Res. 1999;34(1):25-33.

23. Primack BA, Sidani J, Agarwal AA, Shadel WG, Donny EC, Eissenberg TE. Prevalence of and associations with waterpipe tobacco smoking among U.S. university students. Ann Behav Med. 2008;36(1):81-86.

24. Rastam S, Ward KD, Eissenberg T, Maziak W. Estimating the beginning of the waterpipe epidemic in Syria. BMC Public Health. 2004;4:32.

25. Kandela P. Nargile smoking keeps Arabs in Wonderland. Lancet. 2000;356(9236):1175.

26. Akl EA, Jawad M, Lam WY, Co CN, Obeid R, Irani J. Motives, beliefs and attitudes towards waterpipe tobacco smoking: a systematic review. Harm Reduct J. 2013;10:12.

27. Khabour OF, Alsatari ES, Azab M, Alzoubi KH, Sadiq MF. Assessment of genotoxicity of waterpipe and cigarette smoking in lymphocytes using the sister-chromatid exchange assay: a comparative study. Environ Mol Mutagen. 2011;52(3):224-228.

28. Alomari MA, Khabour OF, Alzoubi KH, Shqair DM, Eissenberg T. Central and peripheral cardiovascular changes immediately after waterpipe smoking. Inhal Toxicol. 2014;26(10):579-587.

29. Dexter C, Murray GL, Paulsen IT, Peleg AY. Community-acquired Acinetobacter baumannii: clinical characteristics, epidemiology and pathogenesis. Expert Rev Anti Infect Ther. 2015;13(5):567-573.

30. Hebecker B, Naglik JR, Hube B, Jacobsen ID. Pathogenicity mechanisms and host response during oral Candida albicans infections. Expert Rev Anti Infect Ther. 2014;12(7):867-879.

31. Doughari HJ, Ndakidemi PA, Human IS, Benade S. The ecology, biology and pathogenesis of Acinetobacter spp.: an overview. Microbes Environ. 2011;26(2):101-112.

32. de Vries SP, Bootsma HJ, Hays JP, Hermans PW. Molecular aspects of Moraxella catarrhalis pathogenesis. Microbiol Mol Biol Rev. 2009;73(3):389-406.

33. Perez Vidakovics ML, Riesbeck K. Virulence mechanisms of Moraxella in the pathogenesis of infection. Curr Opin Infect Dis. 2009;22(3):279-285.

34. Cannon RD, Chaffin WL. Oral colonization by Candida albicans. Crit Rev Oral Biol Med. 1999;10(3):359-383.

35. Muzurovic S, Hukic M, Babajic E, Smajic R. The relationship between cigarette smoking and oral colonization with Candida species in healthy adult subjects. Med Glas (Zenica). 2013;10(2):397-399.

36. Alanazi H, Semlali A, Perraud L, Chmielewski W, Zakrzewski A, Rouabhia M. Cigarette smoke-exposed Candida albicans increased chitin production and modulated human fibroblast cell responses. Biomed Res Int. 2014;2014:963156.

37. Takeuchi K, Furuta M, Takeshita T, et al. Serum antibody to Porphyromonas gingivalis and periodontitis progression: the Hisayama Study. J Clin Periodontol. 2015.

38. Parahitiyawa NB, Scully C, Leung WK, Yam WC, Jin LJ, Samaranayake LP. Exploring the oral bacterial flora: current status and future directions. Oral Dis. 2010;16(2):136-145.

39. Eick S, Ramseier CA, Rothenberger K, Bragger U, Buser D, Salvi GE. Microbiota at teeth and implants in partially edentulous patients. A 10-year retrospective study. Clin Oral Implants Res. 2016;27(2):218-225.

40. Karasneh JA, Al Habashneh RA, Marzouka NA, Thornhill MH. Effect of cigarette smoking on subgingival bacteria in healthy subjects and patients with chronic periodontitis. BMC Oral Health. 2017;17(1):64. 
41. Brook I. The impact of smoking on oral and nasopharyngeal bacterial flora. J Dent Res. 2011;90(6):704-710.

42. Shchipkova AY, Nagaraja HN, Kumar PS. Subgingival microbial profiles of smokers with periodontitis. J Dent Res. 2010;89(11):1247-1253.

43. Natto S, Baljoon M, Abanmy A, Bergstrom J. Tobacco smoking and gingival health in a Saudi Arabian population. Oral Health Prev Dent. 2004;2(4):351-357.

44. Masadeh MM, Hussein EI, Alzoubi KH, Khabour O, Shakhatreh MA, Gharaibeh M. Identification, characterization and antibiotic resistance of bacterial isolates obtained from waterpipe device hoses. Int J Environ Res Public Health. 2015;12(5):5108-5115.

45. Obeidat SR, Khabour OF, Alzoubi KH, et al. Prevalence, social acceptance, and awareness of waterpipe smoking among dental university students: a cross sectional survey conducted in Jordan. BMC Res Notes. 2014;7:832.
46. Waziry R, Jawad M, Ballout RA, Al Akel M, Akl EA. The effects of waterpipe tobacco smoking on health outcomes: an updated systematic review and meta-analysis. Int $J$ Epidemiol. 2017;46(1): $32-43$.

47. Chen PC, Pan CC, Kuo C, Lin CP. Risk of oral nonmalignant lesions associated with human papillomavirus infection, betel quid chewing, and cigarette smoking in Taiwan: an integrated molecular and epidemiologic study. Arch Pathol Lab Med. 2006;130(1):57-61.

48. Jawad M, El Kadi L, Mugharbil S, Nakkash R. Waterpipe tobacco smoking legislation and policy enactment: a global analysis. Tob Control. 2015;24 Suppl 1:i60-i65.

49. Ward KD, Siddiqi K, Ahluwalia JS, Alexander AC, Asfar T. Waterpipe tobacco smoking: The critical need for cessation treatment. Drug Alcohol Depend. 2015;153:14-21.
International Journal of General Medicine

\section{Publish your work in this journal}

The International Journal of General Medicine is an international, peer-reviewed open-access journal that focuses on general and internal medicine, pathogenesis, epidemiology, diagnosis, monitoring and treatment protocols. The journal is characterized by the rapid reporting of reviews, original research and clinical studies across all disease areas.

\section{Dovepress}

The manuscript management system is completely online and includes a very quick and fair peer-review system, which is all easy to use. Visit http://www.dovepress.com/testimonials.php to read real quotes from published authors.

Submit your manuscript here: https://www.dovepress.com/international-journal-of-general-medicine-journal 